\title{
Culture Shock in a Study Abroad Program in an Indonesian Context
}

\author{
Arifah Mardiningrum ${ }^{1, *}$ Annisa Larasati ${ }^{2}$ \\ ${ }^{1}$ English Language Education Department, Universitas Muhammadiyah Yogyakarta, Yogyakarta, Indonesia \\ ${ }^{2}$ Department of English, State University of Yogyakarta, Yogyakarta, Indonesia \\ * Email: arifahmardiningrum@umy.ac.id
}

\begin{abstract}
Facing different cultural aspects in a host country can result in a culture shock. The current study investigates the culture shock sources in a Study Abroad program and student participants' strategies to cope with the sources' shock. The study used a qualitative design and involved two students on a Study Abroad program in Yogyakarta, Indonesia. The data collection was done through interviews and written reflective essays. The data showed that languages, foods, clothing, people's character, handshake culture, and traffic became culture shock sources. In the meantime, strategies used to cope with it were categorized into tolerating, adapting, and seeking help. The study could give additional highlights to institutions organizing Study Abroad programs to prepare more effective support programs for the participating students.
\end{abstract}

\section{Keywords: Study Abroad (SA), Culture Shock, Sources of Culture Shock, Coping Strategies}

\section{INTRODUCTION}

Study Abroad (SA) programs, with their promise of many benefits, have been blossoming recently. Although the programs are more familiarly situated in developed countries [1], studying in a developing country like Indonesia seems to appeal. As many as 6,967 Study Permits were issued in 2017 for international students willing to take their education in Indonesian universities, as reported by Patdono Suwignjo, Director General of Institutional Science and Technology of Directorate General Higher Education of Indonesian Republic [2]. Although SA programs in developing countries might not give the same convenience and advanced technology as their developed counterparts might, in a globalized world, it can still be a tool, as Falk and Kanach [1] argued, to bring a discussion and challenge the biased notions of identities and values in between two countries holding the exchange of students. On a similar note, SA programs have reportedly resulted in a more profound social awareness [3], [4], new appreciation to the other culture and own culture [5], and a new acceptance of self-identity [6].
Colored by differing expectations and goals, it is unavoidable that an SA program also challenges its participants in specific ways. The differences between the home country's culture and the host country might cause a clash [7] that an SA participant should consider. This situation can cause a culture shock (CS), which means "anxiety that is caused by loss of familiar social surroundings and exchanges" (Oberg, 1960, as cited in [8], p. 7).

To prevent CS, institutions managing the programs and the host universities usually have organized a plan to prepare the student participants. They could involvesupport system (supervisors), workshops, and pre and post-departure orientation. Despite the many support programs held to help SA students cope with the possible CS, Kelly and Moogan [9] found that CS could still cause lower achievement of the SA students than the host country students, likely because of the CS on the education system. Thus, support programs could only reduce the effects of CS in an SA program. However, the case of CS in SA programs cannot be treated as a one-size-fits-all situation because, in the same study, Kelly and Moogan found that students' achievement differed across ages, genders, and 
semesters. This finding shows that CS is a complicated situation.

The complexity of CS might be due to its differing sources. Some are more familiar in a different context than others. One of the most common sources of CS is language barriers. In a study of SA students in China, Fakir [10] found that SA students struggled with the language and symbols. In line with one of Fakir's findings, Hibatullah [11] found that language issues could also emerge when SA students attend classes where teachers tended to use the local language as the medium of instruction. Thus, this communication barrier also resulted in frustrations in some US students in an SA program in Cambodia in Duerden's [3] study. Consistent with this, research by Yang, Zhang, and Sheldon [12] on international undergraduate students in the US also found that language difficulties became one CS source. In a different study to English teachers taking postgraduate programs in the US, Mardiningrum [13] discovered that even proficient language users, such as English teachers in an SA program in an English speaking country, could experience a shock to find that they still struggled in understanding the host language when used by its native speakers in an authentic context.

Other than the language-related barrier, various sources of CS were found in different studies. Fakir [10] found foods, education (hard to find textbooks), accommodation (expensive), difficulty in performing religious activities, different greetings (the different use of handshake), transportation system, and research works as the sources of students' CS. In terms of foods, a study by Craig, Zou, and Curtis [6] even revealed that a student who was quite familiar with the host country experienced food poisoning by the time she arrived in the country, and this caused a shock and unwillingness to eat more local foods during her stay.

Personal internal aspects can also be the source of $\mathrm{CS}$ in the SA program. The intolerance can cause CS towards the different cultural aspects in the host country [14] or a different expectation to what would be faced before the SA program [3]. Self-determination and age can also influence CS. Yang, Zhang, and Sheldon [12] discovered that the highly self-determined international students had higher essential psychological needs satisfaction and less likely to suffer from CS. They also found that older SA students experienced less CS and theorized that this is due to their better ability to adapt and handle different and new situations. Although the study on adolescent students in an SA program in
Cambodia by Duerden [3] seemed to support this finding, some students in the study, regardless of their relatively young age, showed wisdom and ability to adapt the CS situation quickly and found a quick solution.

The study's distinct different results showed that CS was a personal experience that it was rather complex to see the connecting line in all SA students' cases. Students from the same country joining the same SA program might experience different CS or CS levels. This phenomenon was encountered in the study by Nguyen, Jefferies, and Rojas [4] to US students in an SA program in Puerto Rico and US Virgin Island. In the study, the students experienced marginalization and discrimination by the locals. However, the shock differed between the white monocultural student and the other students identified as African American and Asian. The white monocultural student experienced more shock than the others because they never experienced such treatment in their home country, while other students expressed that it was not something new to them, and therefore, did not shock them.

The optimistic view that one can see from a CS case is that it is likely not permanent because students will adapt in due time. Even with a short term program as short as two to three weeks, an SA program could improve students' cultural adaptability [15]. Anjalin, Mazumdar, and Whiteside [8] found six stages of CS students in an SA program from different cultural backgrounds. The six stages are first, arrival, where students start to feel nervous and exciting at the same time to meet the new culture and situation. Some might also call this the honeymoon phase [7]. The second stage is feeling shocked when students realize they have to face everyday life that might get more challenging and are forced to adjust. The third stage is becoming familiar when students start to accept that their host country is different from their home country.

The next stage is trapped between two worlds, in which students start to experience homesickness and feel that they do not entirely belong to either culture. Taking control is the stage afterward. In this stage, students have gained a sense of confidence because they have been familiar with the situation and have known how to handle everyday problems. The last stage is blending in, where students have felt that they become part of the host university and likely feel more connected to it. It can be seen from these stages that the adverse situation of a CS does not last so long if the 
students stay in the host country at a specific time. They will have the time to adjust. However, such adaption can also be reached in a concise time. A study by Mapp [15] to US students in a short SA program to several countries found a change in cultural adaptability, with emotional resilience as the aspect experiencing the most significant change, followed by flexibility, perceptual equity, and personal autonomy.

Even though CS will likely gradually disappear, some conscious efforts can be done to cope and decrease it so the negative effect might be avoided. Anjalin, Mazumdar, and Whiteside [8] suggested that students receive helps from the host university. This idea is in line with Kelly and Moogan [9], who found that in the third semester, SA graduate students in their study who started to work on their dissertation showed improvement in academic achievement. Kelly and Moogan [9] further analyzed that this improvement was due to one-on-one consultations with their advisors, which meant that they received more individual support regarding their personal issue in campus. The host university can provide the opportunities that allow the SA students in contact with the host community. Jia, Gottardo, Koh, Chen, and Pasquarella [16] found out that the degree of students' contact with the dominant culture group would help the acquisition of the language dominantly used in the host culture, which in the end, would likely help students cope with the everyday challenge since language could be one of the sources of CS.

Besides receiving help from the university or other party, some studies have found that SA students eventually will make some efforts to cope with their CS. English, Zeng, and Ma [17] investigated the coping mechanism of SA students from different ethnicity in China found that non-Asian students used primary and secondary coping controls, while the Asian students only used the primary one. Primary coping is the coping control where students try to modify the negative situation, while the secondary coping control lays within oneself where the students have accepted their changes and growth in the host culture situation [17].

Deliberate actions of coping with CS were also found in Fakir's [10] study. Some students chose to separate themselves from the food culture by cooking their meals and bringing their lunchbox to cope with food CS. To face the CS-related to language, they used non-verbal forms of communication. The problem with accommodation, documentations, academic, and research works chose to build a harmonious relationship with the local students and the community. Collaborating with other SA students is another way to cope with CS, such as the difficulty of religious practice and shopping. The last strategy is to accept the different culture and learn it. Collaborating with local and other SA students can be one way to cope with CS, but not without risk. Schartner [18] found complexities in the social ties between SA students in the UK. In a way, students felt challenges in building social ties with other students from different nationalities. They also still needed social support from their peers of the same nationality; however, in another way, they did not like it when they felt that the contact was too much [18].

With the complexity of $\mathrm{CS}$ in a SA program elaborated above, further study on the topic is still necessary. Therefore, the current study investigates the CS experienced by students in an SA program in the Indonesian context, which is still scarcely done. The study tries to answer two research questions:

1. What are the sources of CS faced by students in an SA program in one Indonesian university?

2. What coping strategies used by the students in facing the CS?

The study is expected to add more understanding of the nature of CS and how students cope with it. The findings might be an additional consideration for institutions responsible for SA programs in creating a support system for SA students.

\section{METHODS}

The current study is qualitative. It focuses on two aspects; the sources of CS faced by the international students and the strategies to overcome the CS. Data were collected through interviews and reflective essays to answer the two research questions. The reflective essay was written based on questions related to the interview guideline. It is essential to mention that the participants had not written as much as an essay should be. Therefore, this issue became one of the limitations of this study. Questions for the reflective essay were first distributed to the two participants. After the participants submitted their reflective essays, an appointment was made with the participants to conduct the interview.

The study was limited to one specific context, namely one private university in Yogyakarta, Indonesia, 
and limited to two international students taking an undergraduate program in English teacher training program. One participant (pseudonym: Lara Jean) was a female student of Taiwanese nationality, while the other one was a female student (pseudonym: Clementine) from Thailand.

Since the topic was closely related to a cultural context, it was imperative to describe the university culture and its surroundings briefly. The university is located in a suburban area around a fifteen-minute ride from the city center. It holds Islamic values that manifest in reading the Quran before a class begins, its academic community's obligation to wear clothing items and hold the values conforming to Islamic teaching. The university is located in one of the regions in Yogyakarta province, a cultural site, which also hosts more than 100 universities with Javanese as the dominant culture.

\section{FINDINGS AND DISCUSSION}

After collecting the data, the researchers then found several findings related to the focus of this study: the sources of CS and the strategies to cope with it.

\subsection{The Sources of Culture Shock}

Collectively, both participants, Lara Jean and Clementine, mentioned seven sources of CS. They comprised languages, foods, clothing, people's character, handshake, traffic. All are elaborated and discussed below, starting from the ones experienced by both participants to the ones experienced by only one of the two.

\subsubsection{Languages}

Lara Jean and Clementine faced the same issue with language differences. Lara Jean had no mastery of the Indonesian language, and Taiwanese is not a familiar language learned by Indonesians, while Clementine had a little understanding of the Indonesian language because her first language is Malay, which holds a similarity to Indonesian. The option was to use English, but they were also not fluent yet, and most people in their host country did not fluently speak the language either. The following is the excerpt of her interview:

“... people cannot speak my language [n]or English, so I need to think the way to talk to them. So, this is about learning experience."

From the excerpt above, there is an indication that even though she mentioned language as one of the things causing her CS, she seems to see it more positively. This result would reflect on how she handled her situation. Meanwhile, although she is from Thailand, Clementine comes from a place where Malay is a local language used every day. Since the Indonesian language was initially based on Malay, Clementine still had a little comfort than Lara Jean in terms of language boundary. However, as mentioned previously, Yogyakarta is an area where Javanese is the dominant culture. It means that the language used by local people is not only Indonesian but also Javanese, the vernacular. It is where Clementine struggled. Language as the source of CS has also been found in previous studies [see $10 ; 11 ; 13 ; 3 ; 12$ ] where students might be struggling because of the different applicable symbols in the local language, the lack of knowledge of the host language, or because of the feeling of not mastering specific languages well. The condition might not show improvement when the SA students had little to no contact with the host country's dominant culture, language acquisition might suffer, and might not solve the CS issue [16].

\subsubsection{Foods}

Lara Jean and Clementine have their issue related to foods in Indonesia. Lara Jean was a vegetarian. She said that it made her feel inconvenient. It is likely because it was rare that a food stall or restaurant serves only vegetarian dishes in the university area, although some possible options might exist. Meanwhile, Clementine tended to like spicy and salty foods as they are some of the familiar characteristics of most Thai foods. In Yogyakarta, many traditional foods tend to taste sweet. The following excerpt from Clementine's essay depicts how she felt.

"The difference that took me a while to adapt is the foods in Jogja because the foods tend to taste sweet, like gudeg. I like foods that taste salty and spicy, and that's why it took me a while to adjust".

CS stems from different food cultures can come from different aspects of the food culture itself. Being a vegetarian is a matter of ideology, and the taste is a matter of what has been a habit. Both could be a challenge, as what Fakir [10] found in his study. Although in Fakir's study, the source of food CS was that the students were not accustomed to using chopsticks, which were familiarly used in the host country, the case was also about food habits. Food difference was likely one of the issues that participants could not easily tolerate, and the intolerance to the host culture is one issue that might cause a CS [14]. 


\subsubsection{Clothing}

Lara Jean and Clementine mentioned this CS source, although they took differing points of view. The following shows what Lara Jean saw:

"Here in campus, I cannot see girls who wear only vest or short pants. Maybe, because it's your religion, but I also think it's a [show of] respect for the teacher. In Taiwan, in campus, when you go to class, you can see girls just wear whatever they want. A short one, or you can see their stomach, or you can see their butt or something".

The shock that girls wear more covering clothing is somewhat contrary to what Clementine saw. Clementine said:

"I think what surprised me was the hijab (head cover). Many of my friends here are Moslems, but they don't wear a hijab. It is normal here, but in Thailand, I rarely saw a female Muslim without her hijab.”

Both participants compared what they saw in the host country to what they saw in their home country, although each saw it differently. According to Oberg, where a CS is from is the absence of what used to be familiar (as cited in [8]). It happened when both participants were still on the first stage of CS that Anjalin, Mazumdar, and Whiteside [8] called arrival, in which the feeling instilled is excitement or nervousness. For Lara Jean and Clementine, this shock did not cause severe anxiety or uneasy feelings.

\subsubsection{People's Characters}

The characters of people in the host country are sources of CS mentioned by both participants. Although both Lara Jean and Clementine did not immediately see the surprise, this category is included in the CS source because, at a certain point, a slight discomfort was caused by it. Lara Jane explained what she thought of people she met in Yogyakarta in the excerpt below:

"Taiwan's culture is a little bit too busy and too fast, and Indonesian's is a little bit slow. It is not bad because they just want to relax or something. The funniest thing I saw was when they are working, and they are singing and just doing their job. They are happy with their job. But in Taiwan, no. Never. Never see that one. No".

Even though in the excerpt, Lara Jean seemed not to see the more relaxed character of people she met in Yogyakarta, she further implicitly expected that they could be less relaxed for a particular need, such as when she needed them in a hustle.
"We were born in Taiwan, and everything is so fast, and we come here, and when we order some food, sometimes, we were in hurry, and they just cook relaxedly and slowly. So maybe, they can... not learn from us, but just be quick. Do their things quickly. Not too fast, not so slow but in the middle".

On the other hand, Clementine found it shocking to see how different people were in Indonesia, unlike her expectation, when she was still in her home country. She said that she expected that Indonesian people would be so much like the people living in Western Thailand, her hometown because most Western Thailand people are also Moslems. However, in her opinion, Indonesians were entirely different in terms of culture, knowledge, and behavior. Although she said that Indonesian people were kind, friendly, and could live together in differences, she stated that she feared that people would not like her because she was different.

Shocked by the different characters of people in a host country is not a new finding. In a way, this finding corroborates the study's finding by Nguyen, Jefferies, and Rojas [4], where the white monocultural student experienced a shock when he felt discriminated against by the local in an SA program. However, Clementine's feeling was an internal fear of being different rather than something caused by the harsh attitude or conduct of other people or the locals. It seems to be a familiar feeling in the arrival stage, where students still feel nervous about different matters [8].

\subsubsection{Handshaking Custom}

As mentioned before arriving in Indonesia, Clementine already had her ideas of what Indonesian people would be like as a community with a Muslim majority. One of the Islamic teachings that she believed in and had been practicing is avoiding skin-to-skin contact between men and women of no familial relationship. Meanwhile, she found out that handshake is a part of Indonesia's culture, especially with older people regardless of gender. In addition to her belief of what Moslem should not do, Clementine's CS was also rooted in Thailand's greeting hand gesture called wai, where a person creates a prayer-like gesture and raise it between their chest and forehead, then they bow. She expressed her shock in the following excerpt:

"Here, it is normal to handshake between women and men, but not in my hometown. It is still haram (forbidden). When I came here, I was surprised when a man offered a handshake with me, but I just accepted it eventually". 
My friends said that it is okay if I did not return the handshake and can do this (pressing her palms together in front of her chest). They said they would understand. But still, I did it once with a boy".

"As far as I know, it is forbidden in Islam for a man and a woman to touch, but after I came here, I felt bad when they already gave their hand, so ... how should I ...?"

Different handshaking custom was also one of the findings in Fakir's [10] study on what caused CS. However, in the current study, the shock did not only stem from different customs but also a religious perspective. From the excerpts above, Clementine's discomfort when she was faced with something against her belief. However, she did not dare to stick to it and finally decided to follow what became the host culture's custom. Her statement was in line with her vulnerability when she said she was afraid of being seen as different in the previous finding. Her action of returning handshake while not being comfortable at the same time seems to be the sign of coming to the last stage of CS that Anjalin, Mazumdar, and Whiteside [8] called blending in

\subsubsection{Traffic}

If the previous finding was the only state by Clementine because of her cultural and religious background, the current finding stems from Lara Jean's home country's condition. She mentioned traffic in Indonesia as one of her CS sources, comparing it to what she used to have in her home country.

"The traffic is dangerous. Motorbikes are everywhere and so close to each other".

"Every time when I am crossing the road, it makes [my] heart bumping so fast."

"... I think the traffic here is so crowded, and the people just drive and ride whatever they want even though the people [are] so close to them, but they still want to go straight, because compared [to] Taiwan, maybe, it's because Taiwan's traffic rule is a little bit strict so this thing never happens in Taiwan".

What Lara Jean felt was something that caused a negative thought. This kind of CS is likely when the students need to use the primary coping mentioned by English, Zeng, and Ma [17], where a student would try to modify the negative situation.

\subsection{Strategies to Overcome Culture Shock}

After presenting the sources of CS, another piece of information found is related to the participants' strategies to overcome the challenges of facing the sources of CS. The findings are presented from the one used for several issues to the one used to overcome particular issues. The strategies are categorized into tolerating, adapting, and seeking helps.

\subsubsection{Tolerating}

Based on the interview and reflective essay result, this strategy is used when facing clothing culture and people's characters. For clothing culture, Lara Jean said that it might be because of the religious value that people had in her host country, dressing differently from the ones in her home country. Meanwhile, Clementine responded that it was okay and did not bother her that not every Muslim girl wore a headcover. She said that she was shocked. This statement shows that these two students show some tolerance for different cultures.

For people's characters, Lara Jean expressed what she thought in the following excerpt:

"I think it's not bad. But ...you can improve. ... Do their things quickly. Not too fast, not so slow but in the middle".

\section{While Clementine said:}

"I think differences are not a problem. So, I'll just [try to] understand the difference and respect that difference and [try] to adapt so I can live in the society".

Both participants did not do specific actions to change the situation but show tolerance and understanding, and for Lara Jean, just a bit of expectation.

Clementine is more into people's tendency to interact with others. Based on the two main issues, the researchers then found two main strategies for dealing with people's character differences. According to Anjalin, Mazumdar, and Whiteside [8], this situation is called the becoming familiar stage, where students in SA programs start to accept the difference that they found in the host country. The fact that both participants could finally understand and tolerate the different situations can also help avoid the severity of their CS because, as Peng [14] argued, intolerance to different cultural aspects might cause CS. 


\subsubsection{Adapting}

The term "adapting" here refers to the self-effort that the participants made to cope with their SC source so they can live together with the host community. The adaptation is to cope with the food difference, handshake culture, and traffic.

Both participants mentioned some issues with the host country's foods; Lara Jean with the lack of vegetarian choices, and Clementine with the taste. They adapted to this situation in the same way. They cooked their food. Lara Jean said she bought a little pot and some vegetables and some sauce to mix in her boarding house. Meanwhile, Clementine showed more efforts:

"So, I looked for a food stall like Padang (a type of food from Sumatra island). Padang is not sweet, right? And sometimes I cooked for myself. ... Although until now I can't [eat] sweet foods, I could adapt by just eating the foods if some lady gave me".

Cooking their meals is not a new strategy chosen by international students. The strategy was also chosen by participants in Fakir's [10] study. Meanwhile, for coping with the handshake culture, Clementine stated that she would do it if she could avoid the handshake. Otherwise, she would just do the handshake because she had become accustomed to it after a while. Lastly, for the traffic-led CS, Lara Jean informed that she needed to be careful, observing how Indonesians crossed the road and tried to imitate them. Of all these strategies to face their CS, both participants showed confidence in handling the situation. This situation might mean that they are already on the stage of taking control, where they know how to cope with everyday tasks [8].

\subsubsection{Seeking for Helps}

Participants used this last strategy to cope with language issues. To overcome the language barrier, Lara Jean said that she used an online translation machine and tried to learn Indonesian language through the course provided for international students. She also used other ways:

"If they cannot understand me, maybe, [I] just use body language. But someone beside me who understands English, they will help me to translate to the local people".

"I learned about the people ... They [are] really kind to help strangers, because in Taiwan, people who don't know each other, they won't help, they won't give a help".
Meanwhile, for Clementine, language is not a big issue since her first language is Malay, which has many similarities to Indonesian. However, it also took her one semester to communicate well. She received help from her friend to learn and practice her Indonesian. Another issue was when she had to face people who spoke the Javanese language, Yogyakarta's local dominant language. She said that she would stay silent or told the people that she did not understand. Lara Jean's way of using body language is in line with Fakir's [10] finding where students used non-verbal communication. In the meantime, connecting with a friend from the host country, who is part of the dominant culture, as Clementine did, can be a solution because it can help the students acquire the target language [16].

\section{CONCLUSION}

Any difference that an SA student finds in a host country can be a source of CS. It is challenging to find one-fits-all solutions to the problem. However, as the current study found, some sources are repeated in different contexts, such as language and foods. Cultural aspects such as religious beliefs and customs resulted from also became the unavoidable source of CS

In the current study and the previous ones, it has been found that students would find a way to cope with any CS source they face in the end. Giving practical support to these students is crucial before some adverse effects occur. It is suggested that institutions holding the SA programs, either as the host or the guess, look into research study results to plan a program to help students effectively avoid CS and prepare a program that normatively should give some needed help.

\section{REFERENCES}

[1] R. Falk, and N. Kanach, "Globalization and study abroad: An illusion of paradox. Frontiers: The Interdisciplinary Journal of Study Abroad," pp. 155-168, 2015.

[2] Ministry of Research and Technology (2017, May 12). "Perguruan tinggi indonesia diminati mahasiswa asing [Indonesian universities are of international students' interest]" May 2017 [Retrieved from https://www.ristekbrin.go.id/siaranpers/perguruan-tinggi-indonesia-diminatimahasiswa-asing-2/]

[3] M. D, Duerden, E. Layland, M. Petriello, A. Stronza, M. Dunn, and S. Adams, "Understanding the unique nature of the adolescent study abroad experience," Journal Of Hospitality, Leisure, Sport \& Tourism Education, vol. 23, pp. 18-28, 2018. 
[4] A. M. D, Nguyen, J. Jefferies, and B. Rojas, "Short term, big impact? Changes in self-efficacy and cultural intelligences, and the adjustment of multicultural and monocultural students abroad," International Journal of Intercultural Relations, vol. 66, pp. 119-129, 2018.

[5] P. Arfiandhani, "Investigating Language Teacher's Sojourn Experiences: Perspectives on Culture," Journal of Foreign Language Teaching and Learning, vol. 2, no. 1, pp. 44-45, 2017.

[6] C. Craig, J. Zou, G. Curtis, "The developing knowledge and identity of an Asian-American teacher: The influence of a China study abroad experience," Learning, Culture and Social Interaction, vol. 17, pp. 1-20, 2018.

[7] M. Mustakim, and U. Jabri, "Overcoming the shock of foreign cultures through cross-cultural understanding," Majesty Journal, vol. 2, no. 2, pp. 24-31, 2020.

[8] U. Anjalin, A. Mazumdar, and E. Whiteside, "Asian students' experience of culture shock and coping strategies," Journal of Education and Social Development, vol. 1, no. 1, pp. 7-13, 2017.

[9] P. Kelly, and Y. Moogan, "Culture shock and higher education performance: Implications for teaching," Higher Education Quarterly, vol. 66, no. 1, pp. 24-46, 2012.

[10] M. S. I, Fakir, "Intercultural adaptation strategies to culture shock of international students in China; A case study," International Journal of Business and Management, vol. 13, no.2, pp. 231-243, 2018.

[11] O. F, Hibatullah, "The challenges of international EFL students to learn English in a non-English speaking country," Journal of Foreign Language Teaching \& Learning, vol. 4, no. 2, pp. 88-105, 2019.

[12] Y. Yang, Y. Zhang, and K.M Sheldon, "Selfdetermined motivation for studying abroad predicts lower culture shock and greater well-being among international students: The mediating role of basic psychological needs satisfaction," International Journal of Intercultural Relations, vol. 63, pp. 95-104, 2018.

[13] A. Mardiningrum, "EFL teachers' linguistic selfconcept in a study abroad program. Journal of Foreign Language Teaching \& Learning," vol. 2, no. 2, pp. 27-37, 2017.

[14] L. A. I, Peng, "Tolerance of ambiguity in culture acquisition-based on differences in cultural perception," Journal of Literature and Art Studies, vol. 8, no. 1, pp. 81-92, 2018.
[15] S. C. Mapp, "Effect of short-term study abroad programs on students' cultural adaptability," Journal of Social Work Education, vol. 48. no. 4, pp. 727-737.

[16] F. Jia, A. Gottardo, P.W, Koh, X. Chen, and A. Pasquarella, "The role of acculturation in reading a second language: Its relation to English literacy skills in immigrant Chinese adolescents," Reading Research Quarterly, vol. 49, no. 2, pp. 251-261, 2014.

[17] A. S, English, Z. J, Zeng, and J. H, Ma, "The stress of studying in China: primary and secondary coping interaction effects," SpringerPlus, vol. 4, no.1, pp. 1-14, 2015.

[18] A. Schartner, "You cannot talk with all of the strangers in a pub': A longitudinal case study of international postgraduate students' social ties at a British university," Higher Education, vol. 69, no. 2, pp. 225-241, 2015. 